\title{
Nuevas geografías urbanas en Santiago de Chile 1992 - 2012. Entre la explosión y la implosión de lo metropolitano'
}

\author{
Luis Fuentes² y Mario Pezoa ${ }^{3}$
}

\begin{abstract}
RESUMEN
En el marco de una discusión sobre la redefinición de lo urbano y las tendencias de crecimiento de la ciudad de Santiago en las últimas décadas, este trabajo analiza la influencia de Santiago sobre su entorno regional y el crecimiento urbano resultante de procesos de explosión e implosión sucedidos en el período 1992 - 2012 que han complejizado los límites reales del Área Metropolitana de Santiago. En primer lugar, mediante la aplicación de la metodología de Áreas Urbanas Funcionales de la OCDE (2012) para los años 2002 - 2012, se redefinen los límites de la ciudad corrigiendo desde las 34 comunas tradicionales a 48 comunas que se dividen en un núcleo y un hinterland, lo que genera una mejor comprensión territorial del fenómeno metropolitano. En segundo lugar, la interpretación supervisada de imágenes satelitales nos permite identificar una nueva forma urbana caracterizada por una nueva geografía, en la cual el crecimiento de las áreas centrales de la ciudad y hacia la periferia se ha dado de forma paralela. La aplicación de metodologías mixtas que analicen lo urbano nos permite comprender que la urbanización es un proceso, en que la forma es solo el resultado de muchos de factores.
\end{abstract}

Palabras clave: Área Urbana Funcional de Santiago, crecimiento urbano, nueva geografía urbana.

\begin{abstract}
Within the framework of a discussion on the redefinition of the urban and the growth trends of the city of Santiago in the last decades, this work analyzes the influence of Santiago on its regional environment and the urban growth resulting from explosion and implosion processes. in the period 1992 - 2012 that have made the real limits of the Metropolitan Area of Santiago more complex. First, through the application of the OECD's Functional Urban Areas methodology (2012) for the years 2002 - 2012, the limits of the city were redefined from the 34 traditional communes to 48 communes that are divided into a nucleus and a hinterland, which generates a better territorial understanding of the metropolitan phenomenon. Secondly, the supervised interpretation of satellite images allows us to identify a new urban form characterized by a new geography, in which the growth within the city and to the periphery has taken place in parallel. The application of mixed methodologies that analyze the urban allows us to understand that urbanization is a process, in which the form is only the result of many factors.
\end{abstract}

Keywords: Urban Functional Area of Santiago, urban growth, new urban geography.

Este trabajo fue posible gracias al Fondo Nacional de Desarrollo Científico y Tecnológico de Chile (FONDECYT), a través del proyecto Fondecyt № 1161550, y la Comisión Nacional de Investigación Científica y Tecnológica (CONICYT), a través del proyecto CONICYT/FONDAP No 15110020. Artículo recibido el 20 de febrero de 2017, aceptado el 12 de julio de 2017 y corregido el 5 de marzo de 2018

Instituto de Estudios Urbanos y Territoriales, Pontificia Universidad Católica de Chile (Chile). E-mail: Ifuentes@uc.cl

Instituto de Estudios Urbanos y Territoriales, Pontificia Universidad Católica de Chile (Chile). E-mail: mapezoa@uc.cl 
Inspirado en la discusión académica sobre la crisis epistemológica de lo urbano, expresado en el debate sobre las nuevas geografías de la urbanización (Brenner, 2014) y sobre la base de la idea del "infilling" (Almagro y Atisba, 2015) o "crecimiento hacia adentro" como única forma de crecimiento de Santiago actual, este trabajo intentará demostrar que en el caso de la capital chilena, las geografías urbanas están adquiriendo nuevas y variopintas morfologías, que hacen descartar la idea simplista de tensionar el debate entre la densificación y el crecimiento en extensión.

El debate mundial en torno a la urbanización se ha dado a propósito de la declaración de la "era urbana" por parte de ONU-Habitat, incentivada sobre todo por el rápido crecimiento del proceso urbano en países como China o la India, transformando al mundo en un planeta urbano. Según Brenner (2013: 41) "esto coincide temporalmente con una serie de transformaciones espaciales, reposicionamientos institucionales y movilizaciones sociales en gran escala, que han intensificado el significado y la magnitud de las condiciones urbanas". Estas nuevas geografías reposicionan la discusión en torno a la definición de lo urbano y cuestionan los criterios que hemos venido utilizando para la definición de los límites de la ciudad, sobre todo por las nuevas morfologías y estructuras variopintas que está adquiriendo la urbanización.

En el contexto local de una discusión sobre los patrones de crecimiento contemporáneos de Santiago, se ha destacado el proceso de verticalización que ha tenido la ciudad, imponiendo la idea de que el resto de los patrones de crecimiento ya no son relevantes, lo cual a nuestro juicio genera varios peligros relacionados a la falta de atención pública sobre la sustentabilidad del crecimiento de la ciudad y la asignación de responsabilidades. Además, es necesario tratar de establecer cuáles son las dimensiones que hoy alcanza la ciudad, toda vez que las relaciones funcionales se han ido complejizando, ampliando su rango geográfico de influencia, tal como lo plantea Dematteis desde el punto de vista teórico (1998: 5): “los nuevos campos de externalidad no tienen ya una forma de área compacta, ni un radio tan limitado, sino que se configuran como retículas articuladas en centros y sistemas urbanos pequeños o grandes, en extensiones territoriales macrorregionales".

Es debido a esta nueva complejidad que se han realizado intentos por redefinir los límites de la ciudad. Desde la tradicional competencia administrativa, hasta indicadores físicos (densidad de edificios, de habitantes, luminosidad) e indicadores funcionales (relación entre lugar de residencia y lugar de trabajo) todos con la intención de redefinir los límites de las áreas urbanas. Entre estos intentos podemos destacar a la FAO (2005) que trabaja con imágenes satelitales de la luminosidad urbana y a la OCDE (2012) que realiza una delimitación funcional de las áreas urbanas en base a criterios de densidad de población y viajes por motivos laborales.

Al respecto este trabajo en primer lugar utilizó la metodología OCDE (2012) para definir el Área Urbana Funcional (FUA ${ }^{4}$ de Santiago con el fin de identificar el alcance de las relaciones que establece el núcleo urbano de Santiago con su Hinterland o área de influencia. Posteriormente, mediante la interpretación supervisada de imágenes satelitales, analizó la evolución de la mancha iluminada y mancha urbana entre los años 1992 y 2012 como forma de representar el crecimiento en extensión de la ciudad, identificando distintos patrones. Finalmente se caracterizó el crecimiento interior de la ciudad mediante el análisis del cambio en la densidad de viviendas de las

Funcional Urban Área, FUA por su sigla en inglés. 
comunas del centro de Santiago. El objetivo fue demostrar una realidad geográfica del fenómeno metropolitano más compleja que la que se caracteriza tradicionalmente con fenómenos que no son opuestos, sino que complementarios y paralelos y que ejercen un alto nivel de influencia sobre el entorno regional.

\section{¿Ciudades o urbanización?}

La ONU plantea que estamos en la era urbana, con más de un $50 \%$ de la población mundial viviendo en ciudades. Esto continúa incrementándose principalmente por el acelerado ritmo de urbanización de América Latina y los países asiáticos donde se están conformando "regiones mega urbanas". Al año 2012 casi el 80\% de la población de América Latina vive en ciudades siendo la región más urbanizada del mundo (ONU, 2012). Sin desconocer esta realidad, aunque con un enfoque diferente basado en la urbanización como una fuerza más que un proceso de concentración de población, algunos autores como Henri Lefebvre (1970) anticiparon este fenómeno y plantearon que el planeta se encontraba ad portas de un proceso de "urbanización completa de la sociedad" en que la diferencia entre lo urbano y lo rural se hace cada vez más difusa. Al respecto, literatura reciente como Brenner \& Schmid (2014); Harvey (2014) y Robinson (2011) hacen una crítica a la medición y al tratamiento de la ciudad como forma universal, tipo de asentamiento o unidad delimitada por relaciones político administrativas. Debido a este tipo de mediciones es que un sin número de investigaciones en temas tradicionales se siguen acumulando y no consideran el fenómeno urbano en su conjunto generando un "campo ciego" (Lefebvre, 1970) en los estudios urbanos.

Distintos autores han realizado aportes para la construcción de una nueva teoría de lo urbano. Según Ananya Roy (2013:820) este es un momento ideal para abrir "nuevas geografías teóricas", posición que comparte Neil Brenner. Algunos más radicales proponen reemplazar los estudios urbanos como algo heredado de la modernidad capitalista, hacia una "sociología de los asentamientos" (Herbert, 2009) que posea una división menos rígida que la basada en límites y diferencias. Brenner \& Schmid (2015), proponen siete tesis para aclarar las apuestas intelectuales y políticas de los debates contemporáneos sobre la cuestión urbana y ofrecer una base analítica para descifrar las rápidamente cambiantes geografías de la urbanización y la lucha urbana en el capitalismo de principios del siglo XXI: (1) lo urbano y la urbanización son categorías teóricas y no objetos empíricos; (2) lo urbano es un proceso no una forma universal, tipo de asentamiento o unidad delimitada; (3) la urbanización implica tres momentos mutuamente constitutivos urbanización concentrada, la urbanización extendida y la urbanización extendida diferencial; (4) la fábrica de la urbanización es multidimensional; (5) la urbanización se ha convertido en planetaria; (6) la urbanización se despliega a través de patrones de desarrollo espacial desigual; y (7) lo urbano es un proyecto colectivo en el que los potenciales generados a través de la urbanización son disputados.

De estas siete tesis es interesante analizar y considerar en este caso la tesis dos, que nos plantea justamente lo urbano como un proceso, ya que está en constante cambio afectado por dinámicas de restructuración socioespacial y procesos de implosión-explosión que apuntalan la producción y reestructuración del espacio (Brenner et al., 2015) o por su posibilidad de recreación constante (Schmid, 2014). Es así como en la actualidad, los visionarios planteamientos de Lefebvre se tornan aún más importantes para construir un nuevo campo teórico de lo urbano. En 
este sentido el término traído de la física atómica para explicar este proceso: el concepto "implosión-explosión", en que como implosión describe la tremenda concentración de la sociedad en una realidad urbana en que la urbanización capitalista "desmantela y reconstituye los centros urbanos e históricos creando formas nuevas, específicamente capitalistas de centralidad urbana" y como explosión la "urbanización capitalista que se extiende por todo el mundo, generando nuevas formas de desarrollo desigual, diferenciación territorial y polarización centro periferia" (Brenner, 2000: 386). Cabe señalar que, en este caso, el concepto de explosión se entenderá como el conjunto de manifestaciones del núcleo urbano sobre su entorno regional, que se expresan en una dependencia funcional o un campo de externalidades que adoptan formas o geografías de la urbanización diferente con una inmensa proyección de distintos fragmentos (periferias, suburbios, ciudades satélites, etc.).

En los últimos años nuevas fuentes de datos basados en satélites, tecnologías SIG han permitido observar estas nuevas geografías de la urbanización desde distintas perspectivas (Brenner, 2013:39). Desde 1972 el proyecto LANDSAT captura imágenes de la superficie terrestre; luego diversos satélites como el SPOT, Quickbird, Kompsat, Rapideye entre otros han aumentado la resolución permitiendo tener una observación que en algunos casos como en el del Worldview 2 llega a 50 centímetros. Autores como Small et al. (2005) identificaron que las áreas urbanas tienden a estar más iluminadas que las áreas rurales durante la noche, por lo que utilizaron imágenes nocturnas del satélite de Defensa y Meteorológico de los Estados Unidos (DMSP-OLS) para identificar las principales aglomeraciones urbanas del mundo y analizar su crecimiento y extensión. En este sentido, recientemente el Banco de Desarrollo de América Latina CAF mediante su Base de Extensión de Áreas Metropolitanas ha medido la extensión de diversas ciudades de la región mediante la "presencia y la expansión de las ciudades (y su área metropolitana) como un conglomerado de pixeles estables de luminosidad nocturna, captados a través de imágenes satelitales" (CAF, 2017: 36). A su vez, este estudio plantea que la luminosidad nocturna no solo es un indicador confiable de la expansión urbana, sino que de la concentración de actividades económicas siendo esta coincidente con la definición de lo urbano planteada por Lefebvre.

En el caso de este estudio, la combinación de imágenes satelitales con datos censales de desplazamiento cotidiano y el uso de Sistemas de Información Geográfica permiten un nuevo entendimiento de lo urbano alejado de las concepciones tradicionales. "La demarcación de los sitios urbanos siempre conlleva complejas maniobras epistemológicas, políticas y cartográficas" (Kahn, 2005: 287) por lo que este estudio pretende ser un aporte en la definición de lo urbano en Santiago.

\section{La reconfiguración de Santiago}

América Latina es la región más urbanizada del planeta llegando a un $80 \%$ de su población viviendo en ciudades, cifra que duplica a África y a Asia y supera a los países desarrollados (ONU, 2012). En el caso de Chile, ya en 1940 el país había sobrepasado la cifra de la mayoría de la población viviendo en ciudades, y esta crecería rápidamente llegando a más del $80 \%$ en 1982. Este rápido proceso de urbanización se desarrolló producto del efecto de las políticas de sustitución de importaciones, las cuales tuvieron como fin el año 1975 y continuó con el proceso de financiarización de la economía chilena, derivado de las reformas estructurales realizadas en la dictadura militar las cuales marcaron el inicio del modelo neoliberal. Este modelo ha generado nuevas 
formas de producción de lo urbano (Cattaneo, 2011; López et al., 2012) lo que ha llevado a una mercantilización del desarrollo urbano (De Mattos, 2008).

En la actualidad, la urbanización en Chile alcanza casi el 90\% de la población, consolidando un modelo de desarrollo territorial concentrado principalmente en ciudades, las cuales ejercen una influencia muy relevante en términos económicos, ya que solo las tres áreas metropolitanas más importantes del país generan el $63 \%$ del PIB. Esta concentración también se da en la zona central del país, ya que actualmente el $60 \%$ de la población de Chile se concentra en lo que a comienzos de la década de 1970 el CIDU ${ }^{5}$ denominó como Macrozona Central (CIDU, 1972). Solo en Santiago vive el $40 \%$ de esta, concentrándose las principales actividades industriales y de servicios.

Diversos autores han estudiado los procesos que han generado una metamorfosis urbana en Santiago de Chile como la importancia de la acumulación capitalista y la financiarización en la restructuración del Área Metropolitana de Santiago (De Mattos, et al. 2014; Cattaneo, 2011), el crecimiento horizontal de la ciudad hacia su periferia basado en la construcción de viviendas sociales y condominios cerrados (Ducci, 1998; Hidalgo, 2007; Grenne, 2004), la restructuración de la ciudad y la generación de subcentros (Ortiz et al., 2005; Truffello et al., 2015), la recuperación de las comunas centrales de Santiago, en especial la comuna homónima en forma de verticalización residencial y sus efectos (Valenzuela, 2003; Contreras, 2011; López et al., 2014; Inzulza, 2014), y los impactos del decreto ley 3.516 sobre subdivisión de predios rústicos que ha permitido el crecimiento infiltrado de la ciudad en áreas rurales mediante la forma de parcelas de agrado (Naranjo, 2009; Armijo, 1997).

A excepción de las investigaciones sobre el periurbano, gran parte de los trabajos siguen analizando a Santiago como una configuración de 34 comunas, área conocida tradicionalmente como "Gran Santiago" sin considerar las características regionales que está tomando la ciudad. Producto de esto, estudios de algunas consultoras (Almagro y Atisba, 2015) plantean que Santiago dejó de crecer horizontalmente entre 2002 - 2012 sin considerar de manera adecuada el efecto que tienen la ampliación del campo de externalidades urbanas sobre la periferia durante estos años. Es por ello que se plantea el desafío de redefinir los límites funcionales de Santiago y tomar en cuenta cada uno de los fenómenos de esta "nueva geografía de la urbanización" para tener una visión completa de lo sucedido en los últimos 20 años.

\section{Metodología para definir los límites de Santiago y sus patrones de crecimiento urbano}

El proceso metodológico se estructuró en dos partes. En primer lugar, se delimitó el Área Urbana Funcional de Santiago, esto con el fin de definir sus límites en función a las relaciones que establece el núcleo urbano de Santiago con su hinterland o área de influencia. Esta se aplicó además para el año 2002 y 2012 con el fin de representar el aumento en la extensión funcional de Santiago, y además también se realizó una proyección de futuro para analizar el aumento en el campo de externalidades de la ciudad. En segundo lugar, se caracterizó la evolución de la mancha iluminada y mancha urbana entre 1992 y 2012 dentro del Área Urbana Funcional de Santiago me-

Centro Interdisciplinario de Desarrollo Urbano, actualmente el Instituto de Estudios Urbanos y Territoriales UC 
diante la interpretación supervisada de imágenes satelitales, permitiendo identificar el crecimiento horizontal y los patrones que ha seguido. Finalmente, con el fin de determinar el crecimiento hacia adentro, se analizaron permisos de edificación de obra nueva y los cambios en la densidad de viviendas de las comunas del centro de Santiago.

\section{Definición del Área Urbana Funcional (FUA)}

La metodología OCDE (2012) de Áreas Urbanas Funcionales delimita áreas urbanas en función de la identificación de núcleos urbanos de concentración de población y áreas de influencia o hinterland definidos mediante relaciones funcionales de movilidad cotidiana por motivo de trabajo. Para identificar la concentración de población, se utilizó como insumo el Landscan Population Dataset 2012 (ORNL, 2012), el cual corresponde a una grilla mundial que posee el dato aproximado de densidad de población a una escala de $1 \mathrm{~km}^{2}$. Para delimitar aquellas comunas que forman parte del hinterland o área de influencia se utilizaron viajes por motivos laborales desde la comuna de residencia a la comuna de trabajo, disponibles en el Levantamiento Censal 2012 realizado por el Instituto Nacional de Estadísticas ${ }^{6}$ y las proyecciones de población al año 2012 para cada comuna.

El Dataset de población fue ingresado al programa ArcGis 10.2 donde, mediante la aplicación de una paleta de colores óptima, fue posible visualizar la densidad identificando una dispersión y gradiente de los valores de densidad más altos a los más bajos. A continuación, se detallan los principales criterios de esta metodología aplicados:

- Se identificaron las celdas de alta densidad ${ }^{7}$. Para esto se reclasificaron los intervalos originales permitiendo representar dos rangos, uno mayor o igual al rango mencionado y otro menor a este;

- Posteriormente, se identificaron aglomeraciones urbanas, las cuales corresponden a un conjunto de áreas densamente pobladas o celdas de alta densidad adyacentes que agrupan más de 50.000 habitantes;

- A continuación, se definieron los núcleos urbanos. Según esta metodología una comuna forma parte de un núcleo urbano si más del $50 \%$ de su población vive en una aglomeración urbana. Un núcleo urbano puede estar formado por una o más comunas;

- Finalmente, se definió el hinterland o área de influencia de cada núcleo urbano, el que corresponde a aquellas comunas que no cumplen con las condiciones para ser consideradas parte de este, pero que envían más del $15 \%$ de su población residente empleada a trabajar a uno de ellos. También se puede identificar como el área de captación de trabajadores del núcleo urbano de Santiago.

Derivado de esta metodología se obtuvieron aquellas comunas que forman parte del núcleo urbano y del hinterland de Santiago para los años 2002 y 2012.

\footnotetext{
Se utiliza el Levantamiento censal INE 2012 y no el Censo 2012 ya que este último no es designado como un censo válido

La OCDE utiliza el umbral 1.500 habitantes por km². Nosotros como un ejercicio metodológico utilizamos el umbral 1.000 habitantes por km² ya que creemos que este umbral refleja mejor la forma de urbanización que está viviendo la macrozona central que concentra fenómenos de verticalización con expansión difusa y de menor densidad como las parcelas de agrado.
} 


\section{Evolución de la mancha iluminada y mancha urbana entre $1992-2012$}

Mediante la interpretación de imágenes satelitales nocturnas obtenidas por el satélite de defensa meteorológico de los Estados Unidos e imágenes satelitales multiespectrales Landsat descargadas desde el visor glovis del Servicio Geológico de los Estados Unidos se determinó la evolución de la mancha iluminada y mancha urbana como dos medidas del crecimiento de las ciudades.

En el caso de la mancha iluminada, esta corresponde a una grilla mundial de luminosidad la cual fue extraída para la zona de estudio mediante el programa ArcGis 10.2. Mediante reclasificación y comparación con imágenes satelitales Landsat se determinó el umbral 45 como aquel que mejor definía la mancha iluminada de la ciudad para los años respectivos, el cual fue luego comparado con la extensión de mancha urbana observándose una clara coincidencia.

En el caso de la mancha urbana, se utilizaron imágenes multiespectrales Landsat con una resolución espacial de 30×30 metros e imágenes satelitales Quickbird con una resolución espacial de $3 \times 3$ metros, estas últimas disponibles en Google Earth. Debido a que las imágenes Landsat corresponden a imágenes multiespectrales, es decir, poseen una imagen captada para cada banda espectral que el sensor pueda captar, fue necesario combinarlas para resaltar el suelo urbano. La combinación usada para las imágenes Landsat TM de 1992 y 2002 fue banda 5 (Infrarrojo lejano), banda 7 (térmico próximo) y banda 1 (visible azul). Para el año 2012 se utilizó imagen Landsat EMT en su banda 8 (monocromático) la cual está disponible en una resolución de $15 \times 15$ metros. Sobre cada una de estas imágenes se delimitó la mancha urbana digitalizando sus contornos y generando un archivo shapefile para cada uno de los años en cuestión. Debido a la baja resolución espacial de LANDSAT ( 30 × 30 metros) se afinaron detalles con imágenes Quickbird del visualizador satelital Google Earth Pro y fotografías aéreas del vuelo SAF OEA de 1994. De la interpretación de las imágenes se obtuvo la mancha urbana de los años 1992, 2002 y 2012 las cuales fueron atributadas con la comuna y zona del Área Urbana Funcional de Santiago que corresponde.

Con estos antecedentes, los resultados se analizaron en función de dos patrones de crecimiento urbano por extensión (Cuadro $N^{\circ} 1$ ).

Cuadro $\mathrm{N}^{\circ} 1$

Patrones de crecimiento urbano por explosión

\begin{tabular}{|l|l|}
\hline Tipo de crecimiento & Criterio \\
\hline Continuo & $\begin{array}{l}\text { Corresponde al crecimiento adyacente a la mancha urbana y a } \\
\text { los asentamientos periféricos existentes en 1992. }\end{array}$ \\
\hline Difuso & $\begin{array}{l}\text { Corresponde al crecimiento discontinuo de la mancha urbana } \\
\text { en forma de nuevas urbanizaciones, tanto parcelas de agrado } \\
\text { como nuevas zonas de desarrollo urbano }\end{array}$ \\
\hline
\end{tabular}

Fuente: Elaboración propia. 


\section{Verticalización}

Para la realización de este objetivo se analizó la superficie de metros cuadrados de obras nuevas (INE, 2015) aprobadas en las comunas del centro del FUA Santiago y los cambios en la densidad de viviendas en estas mismas para los años 1992, 2002 y 2012. Como centro se consideraron aquellas comunas no de borde en que el proceso de crecimiento que se da principalmente por densificación.

\section{Área Urbana Funcional de Santiago}

El Área Urbana Funcional de Santiago (FUA Santiago) forma parte de las nueve áreas urbanas funcionales de la Macrozona Central de Chile. Está compuesta por 48 comunas, 14 más que el Área Metropolitana de Santiago tradicional ya que anexa a comunas como Peñaflor, El Monte, Buin, Paine, Colina, entre otras. De estas 48 comunas, 39 forman parte del núcleo urbano de Santiago, zona que posee un mayor nivel de urbanización debido a la existencia de aglomeraciones urbanas de más de 50.000 habitantes. En el caso del hinterland o área de influencia, este está compuesto por 9 comunas periurbanas que no poseen aglomeraciones de más de 50.000 habitantes pero que igualmente están unidas funcionalmente al núcleo de Santiago mediante el "commuting"s.

Figura $\mathrm{N}^{\circ} 1$

Área Urbana Funcional de Santiago año 2012

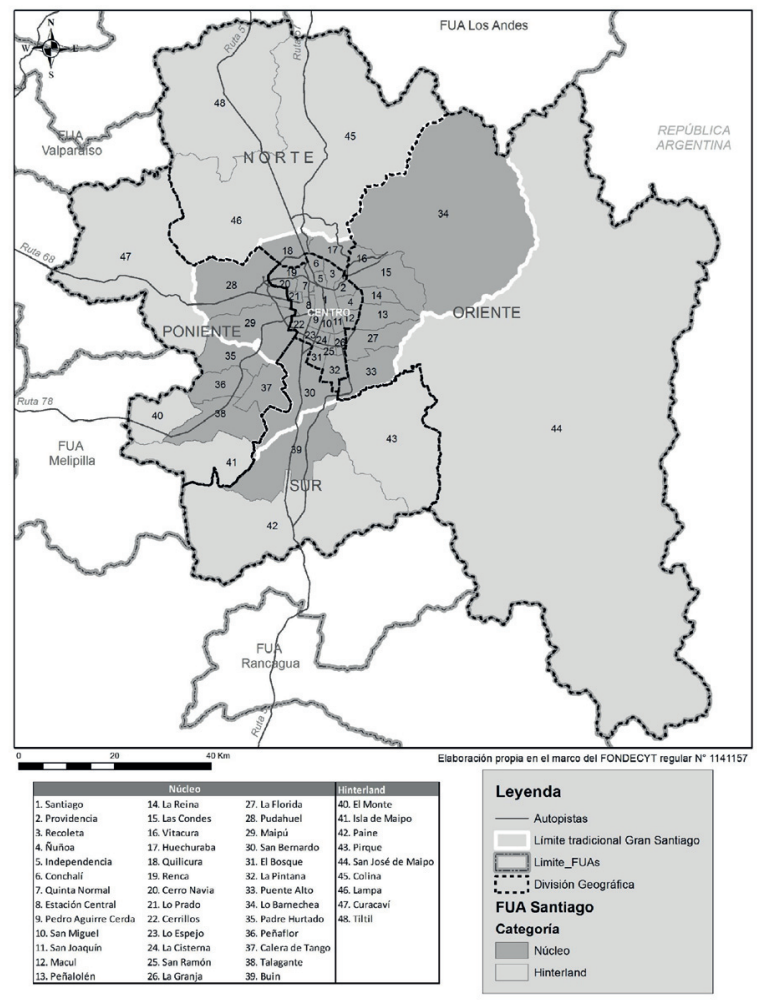

Fuente: Elaboración propia en base a Metodología OCDE. 
De las comunas hinterland Pirque es la que posee mayor cantidad de residentes trabajando en el núcleo urbano de Santiago con un $45 \%$ de su PEA viajando a trabajar al núcleo. Dentro de las comunas del núcleo, a la que más envía trabajadores es a Puente Alto (14,67\%), seguida de Santiago $(7,79 \%)$ y Las Condes (3,3\%). Por otro lado, dentro de las comunas del hinterland, la que envía menor cantidad de trabajadores al núcleo es Til - Til con un 19,22\%, la que igualmente cumple con el umbral de $15 \%$ para pertencer al FUA Santiago.

Al analizar el aporte de cada comuna dentro del contexto total de dependencia funcional del hinterland respecto al núcleo, Colina es la que mayor aporte genera concentrando el $24,2 \%$ de los viajes totales realizados desde el hinterland, seguida de Lampa con 20,7\%, mientras que las comunas que menos porcentaje representan son San José de Maipo con 2,9\% de los viajes totales seguida de Til - Til con 2,3\%. Esto nos habla de la relevancia que ha ido adquiriendo la zona norte de Santiago como lugar de residencia para la población de la ciudad, en un cambio geográfico relevante respecto a lo que fue el crecimiento entre 1992 y 2002, donde Puente Alto y Maipú lideraron el crecimiento.

Figura $\mathrm{N}^{\circ} 2$

Porcentaje de viajes de trabajadores al núcleo desde comunas hinterland por motivo laboral

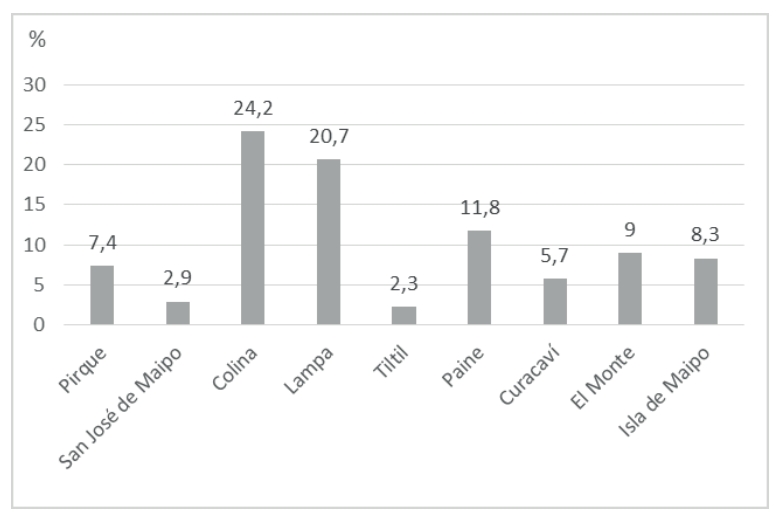

Fuente: Elaboración propia en base a Levantamiento Censal 2012.

Una de las comunas de la Región Metropolitana que no pertenece al Área Urbana Funcional de Santiago corresponde a Melipilla, la que no envía más del $15 \%$ de sus trabajadores al núcleo urbano de Santiago, sino que al año 2012 este porcentaje llega solo a un 10,21\% mientras que el $78,35 \%$ trabaja en la comuna. A pesar de que esta situación -que también se repite en comunas como María Pinto, San Pedro y Alhué- al aplicar la metodología de áreas urbanas funcionales para diferentes años, es posible identificar que existe una tendencia creciente de estas comunas a enviar trabajadores a Santiago, en especial de Melipilla y María Pinto, está última con un $14 \%$ de su población viajando diariamente a trabajar al núcleo urbano de Santiago, por lo cual sería esperable en un futuro muy cercano su anexión funcional al FUA, lo cual acercaría a la ciudad a adquirir una dimensión regional. 
Figura $\mathrm{N}^{\circ} 3$

Evolución Área Urbana Funcional de Santiago 2002 - 2012 y tendencia futura

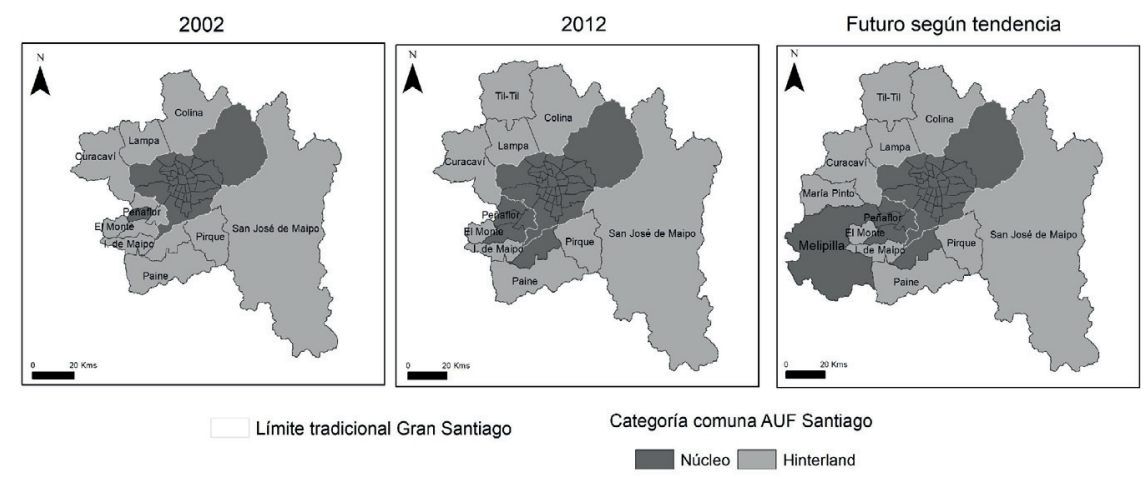

Fuente: Elaboración propia.

Este análisis nos permite observar no solo que los límites funcionales de Santiago son mayores a las tradicionales 34 comunas del Gran Santiago, sino que corresponden a un proceso, ya que están constante cambio con una clara tendencia a ampliar su Hinterland o Área de Influencia hacia la periferia, lo cual le daría una dimensión regional a la capital.

\section{Santiago de Chile, entre la explosión y la implosión de la urbanización}

La tesis que postula este trabajo es que el crecimiento de Santiago se ha complejizado en los últimos años, por lo que tensionar el debate en torno a si la ciudad crece en extensión o en densidad, es una falsa disyuntiva desde el punto de vista de las políticas urbanas.

\section{La explosión de la urbanización en Santiago de Chile entre 1992 y 2012}

1. Mancha iluminada

Al analizar la evolución de la mancha iluminada de Santiago, vemos que esta ha pasado de 72.963 hectáreas en 1992 a 147.394 hectáreas en 2012. Se observa un claro cambio en la mancha iluminada tradicional de una forma compacta en 1992 con algunos pequeños puntos alrededor como Buin, Colina y Talagante. Al año 2002 se observa una expansión hacia el norte y surponiente generando una continuidad entre las manchas que antes se encontraban separadas como Colina que observa claramente unida a Santiago al igual que Talagante y Peñaflor, mientras que Talagante y Buin continúan separados de Santiago. También Lampa y Curacaví alcanzan el umbral de intensidad lumínica y aparecen en el mapa. Al año 2012 vemos una mancha desbordada hacia el norte sur poniente y sur, siendo Colina una extensión de Santiago, mientras que Buin y Paine se unen en un continuo tal como ya había sucedido con Talagante y Peñaflor. Además, nuevas zonas alcanzan el umbral de luminosidad como Isla de Maipo y Til - Til pasando a ser parte de la mancha, 
la que incluso alcanza zonas fuera de la Región Metropolitana de Santiago como San Francisco de Mostazal.

Figura $\mathrm{N}^{\circ} 4$

Evolución de la mancha iluminada de Santiago entre 1992 - 2012
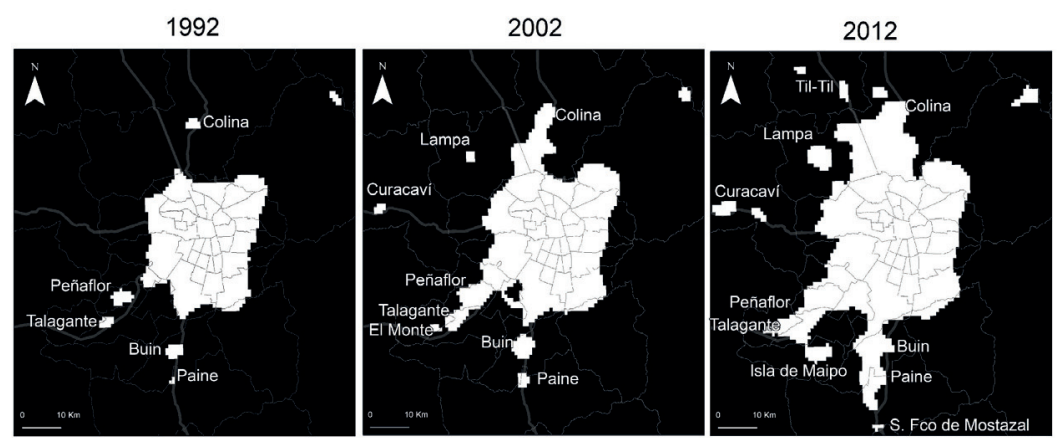

Fuente: Elaboración propia en base a imágenes satelitales nocturnas del satélite DMSP-OLS.

Si bien estos resultados no representan exactamente el área construida ni la mancha urbana de la ciudad como si se muestran en los resultados a continuación, es interesante asociar la aparición de estos puntos iluminados no solo como un aumento en su intensidad lumínica por su crecimiento de población o densidad, sino que tal como plantea $\operatorname{CAF}(2017,37)$ : "la luminosidad como medida de actividad económica permite identificar claramente mercados laborales integrados". En este sentido al comparar los nuevos puntos iluminados 2002 y 2012, gran parte de ellos pasan a formar parte del Área Urbana Funcional de Santiago en el período 2002 - 2012.

\section{Mancha urbana}

Al analizar la evolución de la mancha urbana es posible llegar a una medida más exacta del crecimiento en extensión. Es así como entre 1992 y 2012 esta creció 34 mil hectáreas pasando de 51.906 hectáreas a 85.900 hectáreas. Al igual que la mancha iluminada, se observa una expansión hacia la periferia, pero en este caso en pequeños fragmentos en torno a las principales carreteras que salen de la ciudad siendo el cambio más relevante entre 1992 y 2002, con una consolidación de una mancha con características difusas el año 2012. Una primera constatación es que en su conjunto la ciudad no ha parado de crecer, ya que en términos generales la tasa de consumo de suelo se ha mantenido constante tanto en el primer como en el segundo período, en torno a las 1.650 y 1.750 hectáreas por año respectivamente.

Son varios los fenómenos interesantes de analizar al constatar este crecimiento. Primero que las comunas del poniente de Santiago identificadas en la figura 1 han sido las que más han aportado a la explosión, con un crecimiento horizontal de 10.785 hectáreas entre 1992 y 2012 las que representan el $32 \%$ de la explosión total del FUA de Santiago. El crecimiento difuso representa un $51 \%$ de la expansión de esta zona. 
Figura $N^{\circ} 5$

Evolución de la mancha urbana de Santiago entre 1992 - 2012

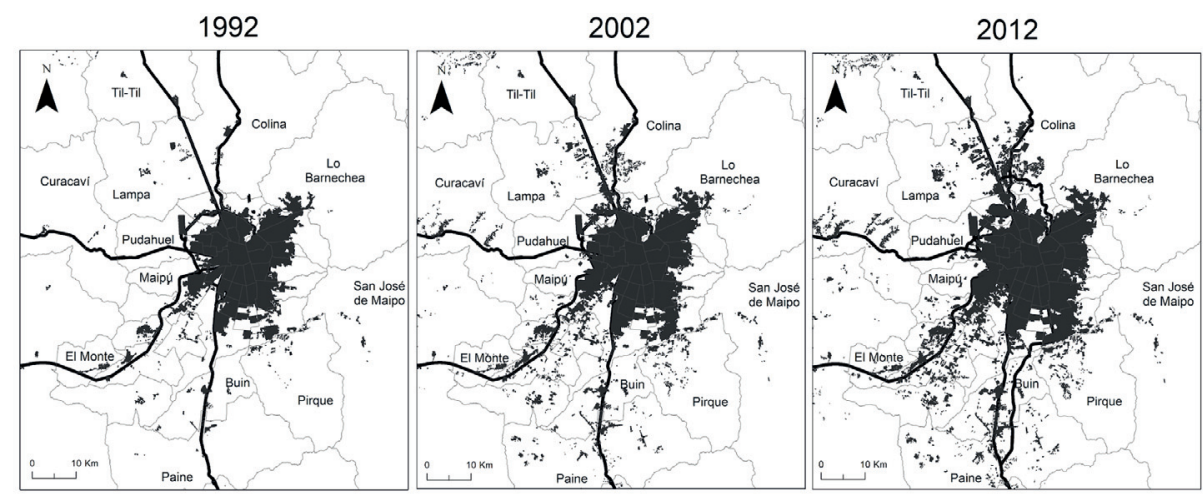

Leyenda

División comunal

Mancha Urbana — Autopistas

Fuente: Elaboración propia en base a imágenes satelitales.

En segundo lugar, se encuentran aquellas comunas del norte de Santiago como Quilicura, Huechuraba, Lampa, Til-Til y Colina, que crecieron 8.468 hectáreas en conjunto siendo Colina la de mayor aumento con 3.356 hectáreas. El crecimiento de este sector representa el 25\% de la explosión total de lo metropolitano, por lo cual el eje norte de la ciudad comienza a adquirir mucha relevancia. El $48 \%$ de la expansión de esta zona corresponde a crecimiento difuso entre parcelas de agrado y áreas de desarrollo urbano condicionado.

En tercer lugar, se encuentra el sector oriente con un crecimiento de 7.094 hectáreas lo que representa el $21 \%$ de la explosión total. El crecimiento de este sector se explica por la expansión de la mancha urbana hacia el piedemonte cordillerano y también hacia el sur-oriente conurbándose con Puente Alto, siendo esta última comuna la de mayor crecimiento con 2.959 hectáreas. El crecimiento continuo es el preponderante con un $93 \%$.

En cuarto lugar, se encuentra la expansión hacia el sur con un crecimiento de 6.188 hectáreas las que representan el $18 \%$ de la explosión total. En esta zona San Bernardo es la comuna de mayor expansión con 2.221 hectáreas. El crecimiento difuso representa un $48 \%$ concentrándose en comunas como Pirque, Paine y Buin mediante la forma de parcelas de agrado.

La identificación de nuevos patrones de crecimiento urbano como el difuso nos habla de una expansión urbana heterogénea en que lo urbano ha tomado distintas manifestaciones. Es así, que el crecimiento continuo en el Área Urbana Funcional de Santiago representa un poco más de la mitad de la explosión, el 38\% corresponde el crecimiento difuso, el cual en algunas zonas como el sector poniente corresponden al patrón de crecimiento preponderante tal como se observa en la Figura $N^{\circ} 6$. 
Cuadro $\mathrm{N}^{\circ} 2$

Evolución de la mancha urbana entre 1992 y 2012 en el FUA de Santiago por zona y tipología

\begin{tabular}{|l|c|c|c|c|c|c|c|c|c|}
\hline & \multicolumn{3}{|c|}{ Crecimiento en hectáreas } & \multicolumn{4}{c|}{ Crecimiento 1992-2012 por zona } & \multirow{2}{*}{$\%$} \\
\hline & $1992-2002$ & $2002-2012$ & $1992-2012$ & Norte & Centro & Sur & Oriente & Poniente & Crecimiento \\
\hline Extensión & 10.836 & 10.122 & 20.958 & 4.422 & 1.459 & 3.206 & 6.626 & 5.245 & 62 \\
\hline Difuso & 5.638 & 7.398 & 13.036 & 4.046 & - & 2.982 & 468 & 5.540 & 38 \\
\hline Total & 16.474 & 17.520 & 33.994 & 8.468 & 1.459 & 6.188 & 7.094 & 10.785 & \\
\hline
\end{tabular}

Fuente: Elaboración propia en base de imágenes satelitales

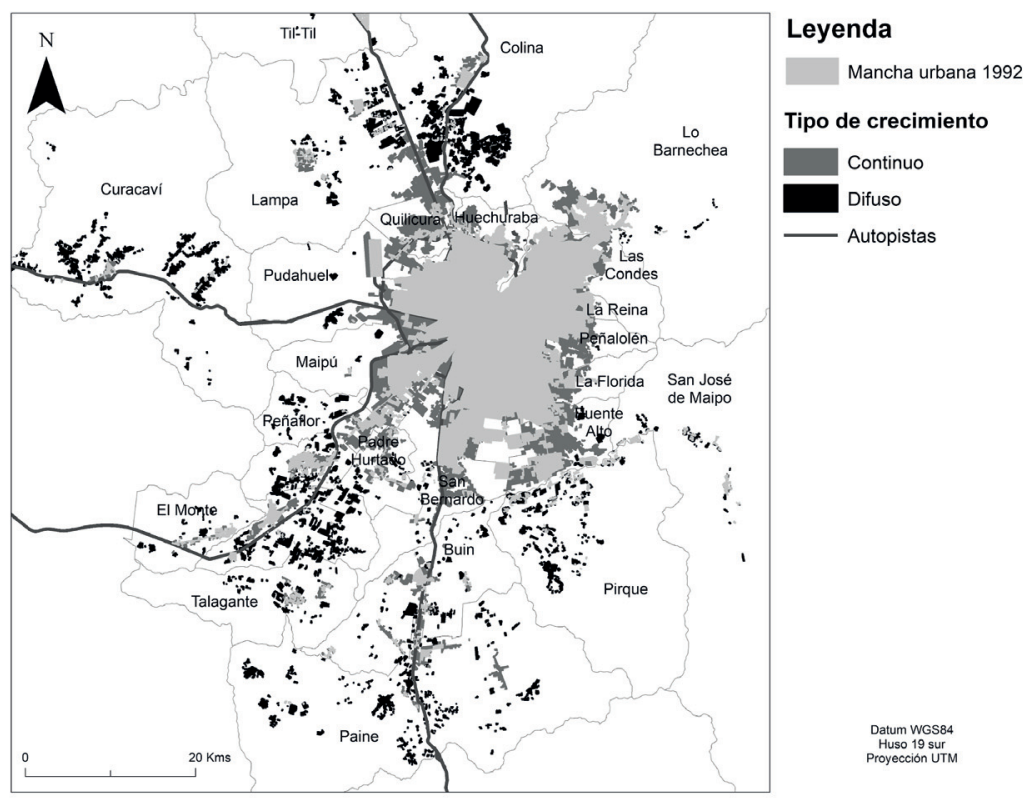

Fuente: Elaboración propia en base a la interpretación de imágenes satelitales.

El crecimiento difuso se presenta principalmente en las comunas del Hinterland como Colina, Talagante, Curacaví y Calera de Tango, donde la urbanización en forma de parcela de agrado ${ }^{9}$ se ha extendido sobre las áreas rurales generando loteos de 5.000 metros cuadrados conectados funcionalmente a la ciudad, tal como lo plantea Naranjo (2009) bajo el concepto ciudad infiltrada.

\footnotetext{
9 Las llamadas "Parcelas de Agrado", corresponde a un tipo de urbanización difusa que amparada en el decreto ley 3.516 de 1980 permite subdividir terrenos rurales en 0,5 hectáreas originalmente con fin agrícola, pero que en la actualidad son de uso residencial, principalmente de clases altas. Fueron identificables mediante criterios morfológicos como su tamaño y la presencia de piscinas, canchas de tenis y jardines en vez de uso agrícola.
} 
Además, en el caso del norte de Santiago el estado ha contribuido a este tipo de crecimiento difuso mediante las Ilamadas Zonas y Proyectos de Desarrollo Urbano Condicionado (ZODUC y PDUC respectivamente) las cuales se conectan al núcleo urbano básicamente por la red de Autopistas Urbanas que salen de la ciudad.

Figura $\mathrm{N}^{\circ} 7$

Crecimiento difuso en forma de parcelas de agrado (izquierda) y zonas de desarrollo urbano condicionado (derecha)
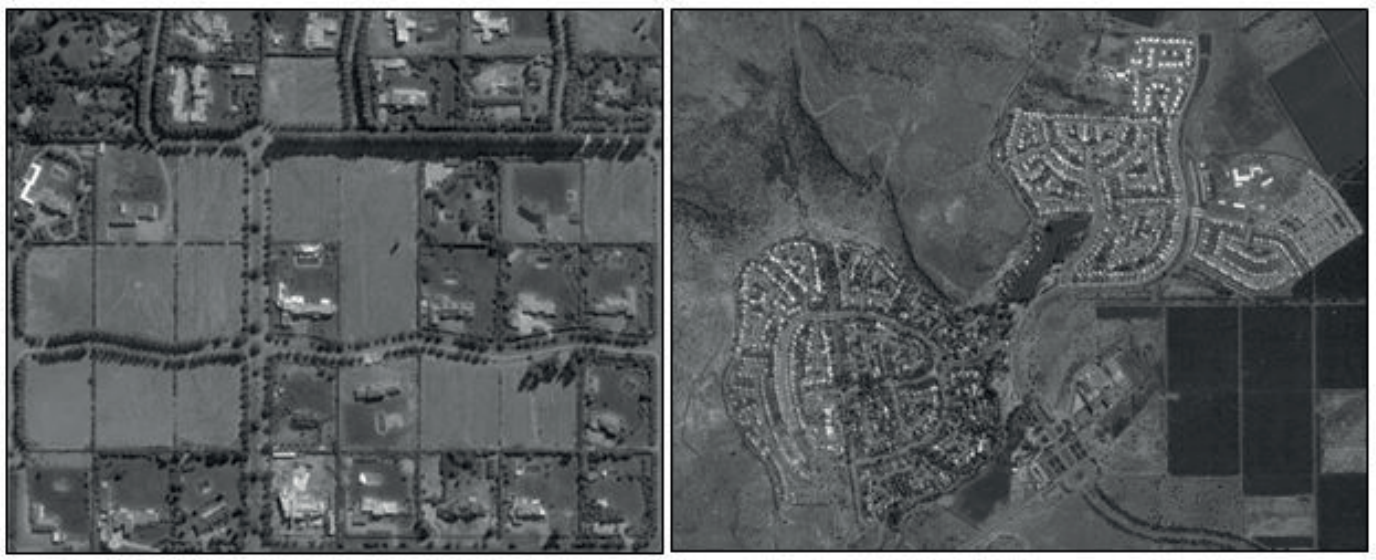

Fuente: Imagen Quickbird 2012 extraída de Google Earth

Es así como lo urbano se ha expresado de distintas maneras en estos últimos años. Paralelamente a esta explosión, una de las tendencias ha sido el crecimiento interior de la ciudad, lo cual se ha dado mediante procesos de destrucción creativa que han transformado barrios residenciales de menor densidad en sectores de departamentos u oficinas, aportando a su vez al repoblamiento del centro de Santiago.

\section{La Implosión de la urbanización}

Incentivado en un primer momento por beneficios estatales al repoblamiento de la comuna de Santiago y posteriormente por el mercado y la valorización de la centralidad como activo para la localización de los habitantes, el fenómeno de densificación de las comunas centrales de Santiago ha sido caracterizado por varios autores desde el punto de vista de sus nuevas geografías socioespaciales (Contreras, 2011), morfológicas y también sus consecuencias en procesos urbanos que López-Morales (2013) ha caracterizado como gentrificación.

Uno de los aspectos que nos permite dar cuenta de este proceso corresponde a la evolución de los permisos de edificación de obra nueva de las comunas del centro de Santiago. Estos nos muestran que entre 1992 y 2012 se aprobaron más de 37 millones de metros cuadrados de obras 
nuevas equivalentes a 3.700 hectáreas de crecimiento por implosión, de los cuales poco más de un tercio corresponde al período 1992 y 2001 y dos tercios entre 2002 y 2012. La vivienda ha sido el principal destino comprendiendo casi el $60 \%$ del total edificado, cifra que se ha incrementado desde el primer período al segundo en más de $6 \%$. Evidentemente, casi el $90 \%$ de los metros cuadrados aprobados son departamentos. La comuna de Santiago es la con mayor superficie de metros cuadrados de obra nueva aprobados con 12.194 .675 de los cuales $7.226 .583 \mathrm{~m} 2$ son departamentos.

Figura $N^{\circ} 8$

Densificación en el distrito censal Vicuña Mackenna de la comuna de Santiago

2002

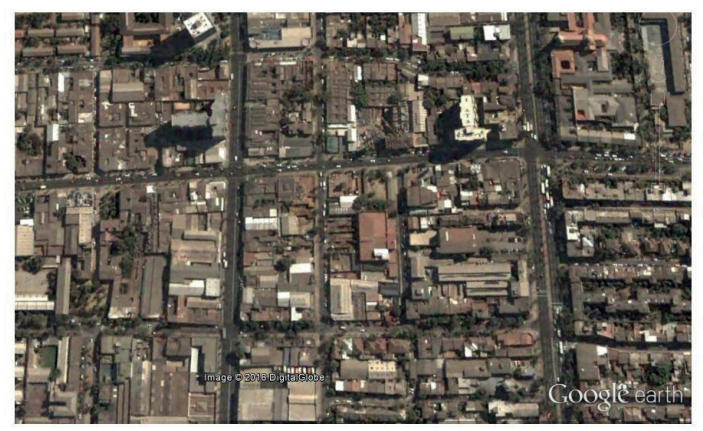

2012

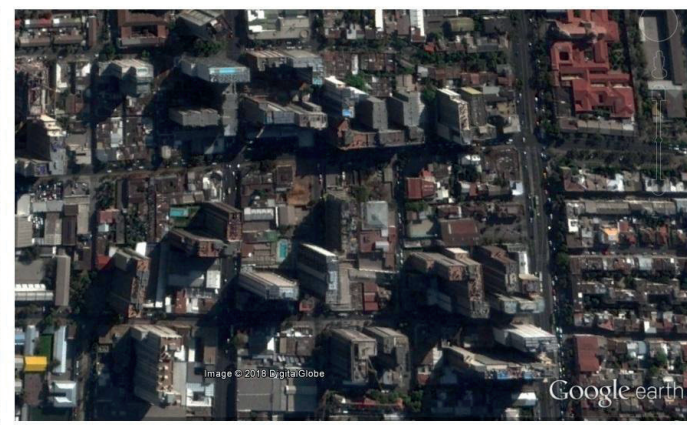

Fuente: Elaboración propia en base a imágenes satelitales Quickbird obtenidas en Google Earth.

Las consecuencias de este proceso de construcción en altura se han reflejado en un aumento en la densidad de viviendas en comunas del centro de Santiago. Es así como el distrito Vicuña Mackenna del cual es posible observar un fragmento de este en la Figura $N^{\circ}$ 8, si en 1992 poseía una densidad de 51 viviendas por hectárea, en 2002 su densidad llegó 153 viviendas por hectárea y ya en 2012 alcanzó las 328 viviendas por hectáreas transformándose en uno de los distritos más densos de Santiago. Situación similar sucedió en otros barrios de comunas como Providencia, Ñuñoa, San Miguel, Recoleta y Las Condes, tal como se observa en la Figura №9.

Este proceso de implosión no solo se ha reflejado en la construcción de edificios de departamentos, sino que tal como plantea Lefebvre, este fenómeno mediante procesos de destrucción creativa genera centralidades, como por ejemplo nuevos distritos de negocios con edificios en altura, como el barrio financiero de Nueva Las Condes, antiguo sector residencial que ha vivido una transformación mediante verticalización y en donde actualmente se localizan las oficinas de las algunas de las principales empresas que operan en el país. 
Figura $N^{\circ} 9$

Evolución de la densidad de viviendas en comunas del centro de Santiago por distrito censal

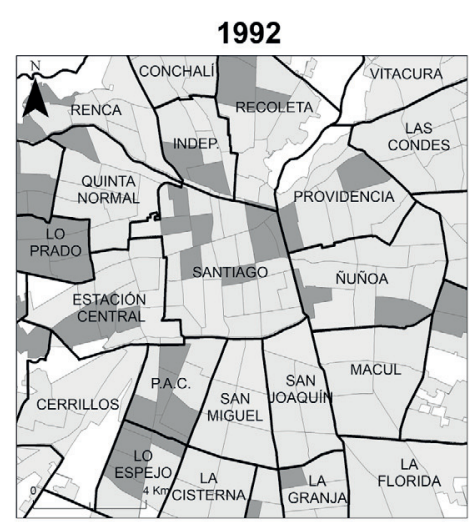

Leyenda

División comunal

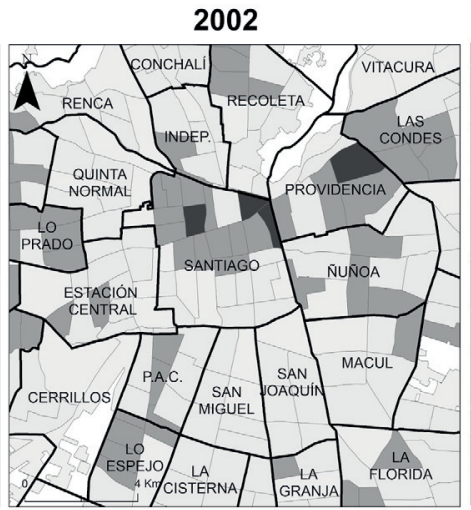

Viviendas por Hectáreas

$20-34 \square 35-59 \square 60-109$

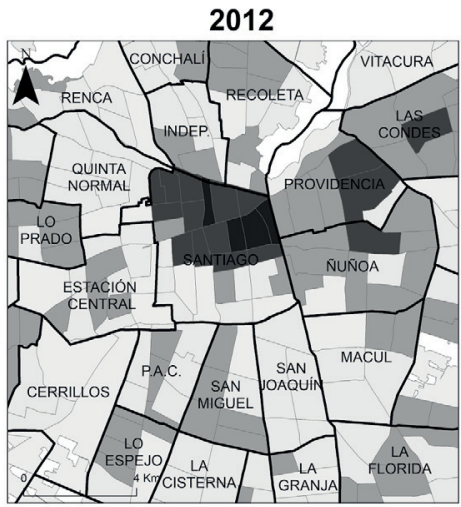

$110-190$

Fuente: Elaboración propia en base a Censos de Población y Vivienda 1992, 2002 y Levantamiento Censal 2012.

Figura $\mathrm{N}^{\circ} 10$

Evolución del distrito financiero de Nueva Las Condes

2002

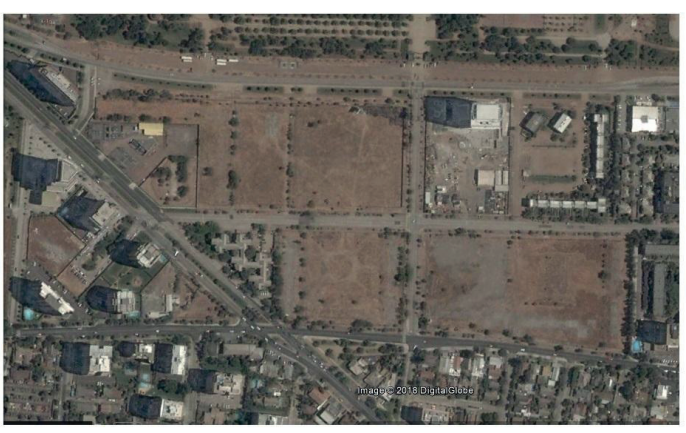

2012

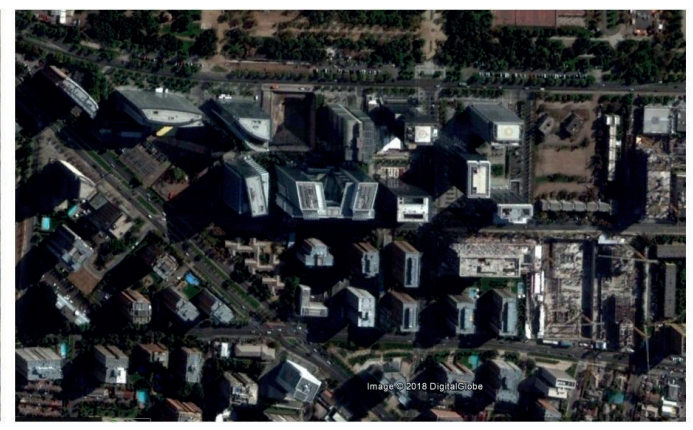

Fuente: Elaboración propia en base a imágenes satelitales Quickbird obtenidas en Google Earth.

\section{Conclusiones}

Después de expuestos los principales antecedentes, tantos teóricos como la evidencia empírica, surgen una serie de aspectos interesantes para la discusión y algunos aprendizajes que pretenden aportar a la discusión y encuadramiento del crecimiento de la urbanización en sus diferentes modalidades. En el caso del contraste que podemos hacer en términos de la caracteriza- 
ción del crecimiento de Santiago en función de la discusión académica sobre lo urbano es posible plantear que lo que ocurre en Santiago responde a lo planteado por Schmid (2014) en cuanto a que el fenómeno urbano se caracteriza por sus diferencias, no por sus particularidades. Un solo estilo de vida urbano no es real ya que el crecimiento de la ciudad genera distintos hábitats. Por estas razones, se plantea la necesidad de comprender, investigar el funcionamiento de Santiago desde la perspectiva de sus relaciones funcionales y la complejidad de sus formas de crecimiento con el fin de planificarla de una manera que mejore la calidad de vida de todos los habitantes de su Área Urbana Funcional.

Desde otra perspectiva, y concluyendo exclusivamente sobre la evidencia empírica mostrada anteriormente y teniendo como perspectiva la discusión sobre las tendencias de crecimiento urbano de Santiago y la delimitación de la ciudad es posible plantear las siguientes ideas:

- Sobre la delimitación del FUA de Santiago y el análisis de la evolución de la mancha urbana es importante plantear que en primer lugar Santiago no puede seguir considerándose como la conurbación tradicional de 34 comunas, por lo que es necesario establecer criterios funcionales que consideren las tendencias de crecimiento y el rol de la movilidad entre los distintos centros urbanos de la región. Esto permite obtener como resultado un área urbana funcional de dimensiones casi regionales y en constante expansión. La exclusión de otras comunas de la Región Metropolitana del FUA de Santiago, como Melipilla, Alhué, San Pedro y María Pinto nos permiten delimitar hasta donde llega Santiago funcionalmente, y nos alientan a estudiar las dinámicas propias de esas comunas - tanto en relación a su mercado de trabajo como al crecimiento urbano - y a desarrollar políticas regionales que consideren esta situación y las dimensiones actuales de la urbanización como fenómeno que excede y "burla" los límites administrativos.

- El crecimiento de Santiago mezcla fenómenos de implosión y explosión, siendo en el primer caso el repoblamiento del centro y preicentro de Santiago uno de los principales responsables y en el segundo caso, el crecimiento difuso las cuales forman una periferia compleja en un paisaje rural pero funcionalmente urbano.

- El crecimiento de la mancha urbana de Santiago no se ha desacelerado en la última década como plantean otros estudios, sino que, al contrario, se ha mantenido constante. Al realizar el análisis diferenciando entre núcleo e hinterland podemos determinar que es la periferia la que está creciendo a pasos acelerados aportando a la conformación de una mancha discontinua y difusa. El crecimiento hacia el norte de Santiago ha sido considerable, especialmente en el valle de Chicureo donde observamos nuevas formas de urbanización conviviendo parcelas de agrado con la mancha urbana difusa. Las parcelas de agrado han sido un fenómeno importante para consolidar este Santiago de características regionales. Su proliferación desde 1992 ha ido en aumento y su localización se da cada vez más hacia la periferia.

\section{Referencias bibliográficas}

ALMAGRO \& ATISBA. Infilling: Cómo cambió Santiago y nuestra forma de vivir la ciudad. Santiago de Chile: Editorial Hueders, 2015. 
ARMIJO, G. y CAVIEDES, H. El avance de la urbanización del campo en la Región Metropolitana de Chile y sus efectos espaciales. Anales de la Universidad de Chile, 1997, Sexta Serie (5). Disponible en Internet:

http://www.anales.uchile.cl/index.php/ANUC/article/viewFile/2985/2863

BRENNER, N. The Urban Question as a Scale Question. Reflections on Henri Lefebvre, Urban Theory and the Politics of Scale. International Journal of Urban and Regional Research, 2000, Vol. 24, $\mathrm{N}^{\circ}$ 2. Disponible en Internet:

https://onlinelibrary.wiley.com/doi/epdf/10.1111/1468-2427.00234

BRENNER, N. Tesis sobre la urbanización planetaria. Nueva Sociedad, 2013, № 243, p. 38-66.

BRENNER, N. \& SCHMID, C. The 'Urban Age' in Question. International Journal of Urban and Regional Research, 2014, Vol. 38, № 3. Disponible en Internet:

https://onlinelibrary.wiley.com/doi/epdf/10.1111/1468-2427.12115

BRENNER, N. \& SCHMID, C. Towards a new epistemology of the urban? City, 2015, № 19, p. 151-182.

CAF BANCO DE DESARROLLO DE AMÉRICA LATINA. Crecimiento Urbano y acceso a oportunidades: un desafío para América Latina. 2017. Disponible en Internet:

http://scioteca.caf.com/handle/123456789/1090

CATTANEO, R. Los fondos de inversión inmobiliaria y la producción privada de vivienda en Santiago de Chile: ¿Un nuevo paso hacia la financiarización de la ciudad? EURE, 2011, Vol. 37, №112, p. 5-22.

CIDU. Síntesis del estudio región central de Chile: perspectivas de desarrollo. Santiago de Chile, U.C.-CIDU, 1972.

CONTRERAS GATICA, Y. La recuperación urbana y residencial del centro de Santiago: Nuevos habitantes, cambios socioespaciales significativos. EURE, 2011, Vol.37, No 112, p. 89-113.

DE MATTOS, C. Globalización, negocios inmobiliarios y mercantilización del desarrollo urbano. En: PEREIRA, P.C.X. e HIDALGO, R. (editores). Producción inmobiliaria y reestructuración metropolitana en América Latina. Santiago de Chile: Serie GeoLibros No 11, Instituto de Geografía, Pontificia Universidad Católica de Chile / Facultad de Arquitectura y Urbanismo de la Universidad de Sao Paulo, 2008. p. 23-40.

DE MATTOS, C.; FUENTES, L. y LINK, F. Tendencias recientes del crecimiento metropolitano en Santiago de Chile: ¿Hacia una nueva geografía urbana?. Revista INVI, 2014, Vol.29, Nº 81, p. 193219.

DEMATTEIS, G. Suburbanización y periurbanización. Ciudades anglosajonas y ciudades latinas. En: MONCLUS, F. (editor). La ciudad dispersa. Suburbanización y nuevas periferias. Barcelona: Centre de Cultura Contemporánia de Barcelona, 1998. p. 17-34. 
DUCCI, M. Santiago, ¿una mancha de aceite sin fin?¿Qué pasa con la población cuando la ciudad crece indiscriminadamente?. EURE, 1998, Vol. 24, Nº 72, p. 85-94.

FOOD AND AGRICULTURE ORGANIZATION (FAO). Mapping global urban and rural population distributions. Roma: Natural Resources Management and Enviromental Departament, 2005. Disponible en Internet: http://www.fao.org/docrep/009/a0310e/a0310e00.htm

GREENE, M. y SOLER, F. Santiago: de un proceso acelerado de crecimiento a uno de transformaciones. En: DE MATTOS, C.; DUCCI, M.E.; RODRÍGUEZ, A. y YÁÑEZ WARNER, G. (editores). Santiago en la globalización: ¿una nueva ciudad? Santiago de Chile: Ediciones SUR/EURE Libros, 2004, p. 47-84.

HARVEY, D. Seventeen Contradictions and the End of Capitalism. Oxford: Oxford University Press, 2014.

HERBERT, G. Some Problems of and Futures for Urban Sociology: Toward a Sociology of Settlements. City \& Community, 2009, Vol. 8, №3. Disponible en Internet: https://onlinelibrary.wiley.com/doi/epdf/10.1111/j.1540-6040.2009.01286.x

HIDALGO, R.; BORSDORF, A. y SÁNCHEZ, R. La expansión residencial amurallada en la reconfiguración metropolitana de Santiago de Chile. En: MATTOS, C. e HIDALGO, R. (editores). Movilidad espacial y reconfiguración metropolitana. Santiago de Chile: Colección EURE-Libros, Instituto de Estudios Urbanos y Territoriales; SERIE GEOlibros Nº 8, Instituto de Geografía, Pontificia Universidad Católica de Chile, 2007, p. 132-156.

KAHN, A. Defining Urban Sites. In: BURNS, C. \& KAHN, A. Site Matters: Design Concepts, Histories, and Strategies. Nueva York: Routledge, 2005, p. 287.

GANS, H. Some Problems of and Futures for Urban Sociology: Toward a Sociology of Settlements. City \& Community, 2009, Vol. 8, No 3. Disponible en Internet: https://onlinelibrary.wiley.com/doi/epdf/10.1111/j.1540-6040.2009.01286.x

INSTITUTO NACIONAL DE ESTADÍSTICAS (INE). Superficie en obras nuevas autorizadas por destino. Santiago de Chile: Series estadísticas, 2015.

INZUNZA, J. y GALLEGUILLOS, X. Latino gentrificación y polarización: transformaciones socioespaciales en barrios pericentrales y periféricos de Santiago, Chile. Revista de Geografía Norte Grande, 2014, N 58, p. 135-159.

LEFEBVRE, H. La revolution urbaine. Paris: Gallimard, 1970.

LOPEZ-MORALES, E. Gentrificación en Chile: aportes conceptuales y evidencias para una discusión necesaria. Revista de Geografía Norte Grande, 2013, N 56, p. 31-52.

LOPEZ-MORALES, E.; GASIC KLETT, I. y MEZA CORVALAN, D. Urbanismo pro-empresarial en Chile: políticas y planificación de la producción residencial en altura en el pericentro del Gran Santiago. Revista INVI, 2012, Vol. 27, № 76, p. 75-114. 
LOPEZ-MORALES, E.; MEZA, D. \& GASIC KLETT, I. Neoliberalismo, regulación ad-hoc de suelo y gentrificación: el historial de la renovación urbana del sector Santa Isabel, Santiago. Revista de Geografía Norte Grande, 2014, № 58, p. 161-177.

MINISTERIO DE AGRICULTURA. Decreto Ley 3516 de subdivisión de predios rústicos. Santiago de Chile: Publicado en el Diario oficial №30.829 de 1 de diciembre de 1980.

NARANJO, G. El rol de la ciudad infiltrada en la reconfiguración de la periferia metropolitana. Revista Estudios Geográficos, 2009, Vol. LXX, №266, p. 205-229.

ORGANIZACIÓN PARA LA COOPERACIÓN Y EL DESARROLLO ECONÓMICOS (OCDE). Redefining "Urban". A new way to mesaure metropolitan areas. Paris: OECD, 2012.

ONU-HABITAT. Estado de las ciudades de América Latina y el Caribe. Rumbo a la nueva transición urbana. Rio de Janeiro: UN-HABITAT, 2012.

ORNL. Landscan population Dataset 2012. Office of Science. Washington: U.S Departament of Energy, U.S Government.

ORTIZ, J; ESCOLANO, S. Crecimiento periférico del Gran Santiago. ¿hacia la desconcentración funcional de la ciudad? Scripta Nova. Revista Electrónica de Geografía y Ciencias Sociales, 2005, Vol. IX, No 194 (04). Disponible en Internet: http://www.ub.es/geocrit/sn/sn-194-04.htm

PEZOA, M. Macrozona Central de Chile. Hacia una Región Urbana de Nuevas Geografías. Santiago de Chile: Tesis para obtener el grado de Magister en Desarrollo Urbano, Instituto de Estudios Urbanos y Territoriales, Pontificia Universidad Católica de Chile, , 2017

PROCTOR, R. \& SCHIEBINGER, L. (editors). Agnotology: The making and unmaking of ignorance Palo alto: Stanford University Press 2008.

ROBINSON, J. Cities in a World of Cities: The Comparative Gesture. International Journal of Urban and Regional Research, Vol. 35, N 1. Disponible en Internet:

https://onlinelibrary.wiley.com/doi/epdf/10.1111/j.1468-2427.2010.00982.x

ROY, A. Las metrópolis del siglo XXI. Nuevas geografías de la teoría". Andamios. Revista de Investigación Social, 2013, Vol. 10, N²2, p. $149-182$.

SCHMID, C. Networks, Borders, Differences: Towards a Theory of the Urban. In: Brenner, N. (editor). Implosions/Explosions: Towards a Study of Planetary Urbanization. Berlin: Jovis, 2014, p. 67-85.

SMALL, C.; POZZI, F. \& ELVIDGE, C.D. Spatial analysis of global urban extent from DMSP-OLS night lights. Remote Sensing of Environment, 2005, N 96, p. 277 - 291.

SLATER, T. When Opinion Becomes Fact: Free Market Think Tnaks and the UK Housing Crisis. En: Resumen de Charla Magistral en el marco de la Conferencia Anual del Centro de Estudios de Conflicto y Cohesión Social COES titulada "Conflictos urbanos y territoriales: ¿desafiando la cohesión social?", Santiago de Chile, 2015. 
TRUFFELLO, R. y HIDALGO, R. Policentrismo en el Área Metropolitana de Santiago de Chile: reestructuración comercial, movilidad y tipificación de subcentros. EURE, 2015, Vol.41, №122, p. 49-73.

VALENZUELA, M. Programa de repoblamiento comuna de Santiago: Un programa de gestión urbana. Urbano, 2003, Vol. 6, Nº 8, p. 53-61. 
